\section{Epithelial-specific knockout of the Rac1 gene leads to enamel defects}

Huang Z, Kim J, Lacruz RS, Bringas P Jr, Glogauer M, Bromage TG, Kaartinen VM, Snead ML. Epithelial-specific knockout of the Rac1 gene leads to enamel defects. Eur J Oral Sci 2011; 119 (Suppl. 1): 168-176. (C) 2011 Eur J Oral Sci

The Ras-related C3 botulinum toxin substrate 1 ( Racl) gene encodes a 21-kDa GTPbinding protein belonging to the RAS superfamily. RAS members play important roles in controlling focal adhesion complex formation and cytoskeleton contraction, activities with consequences for cell growth, adhesion, migration, and differentiation. To examine the role(s) played by $\mathrm{RACl}$ protein in cell-matrix interactions and enamel matrix biomineralization, we used the $\operatorname{Cre} / \operatorname{lox} P$ binary recombination system to characterize the expression of enamel matrix proteins and enamel formation in $\mathrm{Racl}$ knockout mice $\left(\mathrm{Racl}^{-/}\right)$. Mating between mice bearing the floxed $\mathrm{Racl}$ allele and mice bearing a cytokeratin 14-Cre transgene generated mice in which Racl was absent from epithelial organs. Enamel of the Racl conditional knockout mouse was characterized by light microscopy, backscattered electron imaging in the scanning electron microscope, microcomputed tomography, and histochemistry. Enamel matrix protein expression was analyzed by western blotting. Major findings showed that the Tomes processes of $\mathrm{Racl}^{--}$ameloblasts lose contact with the forming enamel matrix in unerupted teeth, the amounts of amelogenin and ameloblastin are reduced in $\mathrm{Racl}^{-/}$ ameloblasts, and after eruption, the enamel from $\mathrm{Racl}^{-/-}$mice displays severe structural defects with a complete loss of enamel. These results support an essential role for $\mathrm{RACl}$ in the dental epithelium involving cell-matrix interactions and matrix biomineralization.
Zhan Huang ${ }^{1}$, Jieun $\mathrm{Kim}^{2}$, Rodrigo

S. Lacruz ${ }^{1}$, Pablo Bringas $\mathrm{Jr}^{1}$, Michael Glogauer ${ }^{3}$, Timothy G. Bromage $^{4}$, Vesa M. Kaartinen ${ }^{2}$, Malcolm L. Snead ${ }^{1}$

${ }^{1}$ The Center for Craniofacial Molecular Biology, Herman Ostrow School of Dentistry, University of Southern California, Los Angeles, CA, USA; ${ }^{2}$ Department of Biologic and Materials Sciences, School of Dentistry, University of Michigan, Ann Arbor, MI, USA; ${ }^{3}$ Matrix Dynamics Group, Faculty of Dentistry, University of Toronto, Toronto, Ontario, Canada; ${ }^{4}$ New York University College of Dentistry, New York, NY, USA

Zhan Huang, The Center for Craniofacial Molecular Biology, The Herman Ostrow School of Dentistry, University of Southern California, HSC, CSA 1422250 Alcazar Street, Los Angeles, CA 90033, USA

Telefax: +1-323-4422981

E-mail: zhanhuan@usc.edu

Key words: ameloblast; cell adhesion; epithelial cell; extracellular matrix; Rac1

Accepted for publication September 2011
Enamel, the hardest and most mineralized tissue in the vertebrate body, is formed by ameloblasts through the coordinated processes of morphogenesis and cytodifferentiation, which are signaled by sequential and reciprocal epithelial-mesenchymal interactions (1-3).

Ras-related C3 botulinum toxin substrate 1 (RAC1), a 21-kDa small GTP-binding protein, belongs to the RAS superfamily whose members play important roles in controlling cell growth, migration, and differentiation. RAC1 proteins are required for assembly of the actin cytoskeleton and their associated focal complexes, and are essential for the formation of three germ layers during early mouse embryogenesis $(4,5)$.

Deletion of Racl in murine neural crest cells results in abnormal craniofacial development with clefting at embryonic day 12 (E12), evidenced by disrupted integrity of the craniofacial and pharyngeal mesenchyme. Animals with the binary deletion (Racl/Wnt1-Cre) die at an early embryonic stage (6). Racl-null mouse embryonic fibroblasts are contracted in morphology and defective in lamellipodia formation, cell spreading, cell-fibronectin adhesion, and focal contact formation in response to platelet-derived growth factor or serum (7). Animals with the binary deletion (Racl/cytokeratin 14) exhibit a clearly delayed closure and healing of cutaneous and oral wounds (8). Whether RAC1 is required for enamel development is not fully understood. To investigate the role played by RAC1 in cell-matrix interactions and in subsequent matrix biomineralization during enamel formation, we used the Cre/loxP recombination system to characterize enamel matrix protein expression in Racl conditional knockout mice in which the cytokeratin 14 (keratin 14) promoter drives Cre expression in epithelial organs.

Integrin cell receptors on the ameloblast surface have been shown to participate in amelogenesis by mediating cell adhesion with the enamel extracellular matrix proteins through several ligands and specific signals that result from these interactions (9-11). Integrin $\alpha 6 \beta 4$ interacts with the laminin $\alpha 5$ chain and regulates the cell polarity of inner dental epithelium via the RAC/CDC42 pathway, thus participating in determining the start of ameloblast differentiation (12). On the other hand, attachment of cells to the extracellular matrix results in the clustering of integrins and the formation of focal complexes, which are associated with a variety of dynamic changes in cytoplasmic proteins and the organization of the actin cytoskeleton for maintaining cell growth, survival, and directing cell migration (13). It has been suggested that the cytoskeletal organization in ameloblasts may determine the formation of distal terminal junction complexes and the cyclic activity of ameloblast secretory end-pieces known as Tomes' processes and be involved in pattern formation of the enamel matrix (14-17). 


\section{Material and methods}

\section{Mouse preparation}

The Keratin 14 promoter (K14)-Cre transgenic line, and the $\operatorname{Racl}^{\mathrm{fl} / \mathrm{fl}}$ (fl, flanked by loxP sites) mouse stain have been described previously $(4,6,18)$. Mating $\mathrm{K} 14-\mathrm{Cr}^{+/-}$with $\mathrm{fl} / \mathrm{fl}$ $\left(\right.$ Racl $\left.^{\mathrm{fl} / \mathrm{fl}}\right)$ mice generated wild-type/fl and K14-Cre mice. Subsequent mating between wild-type/fl; K14-Cre mice generated $\mathrm{fl} / \mathrm{fl}$ and $\mathrm{K} 14-\mathrm{Cre}$ homozygous conditional Racl knockout mice. For ease of identification, we refer to the wild-type animal as $\mathrm{Racl}^{+/+}$(WT), the wild-type/fl; K14Cre animal as $\mathrm{Racl}^{+/-}$, and the $\mathrm{fl} / \mathrm{fl}$; K14-Cre animal as $\mathrm{RaCl}^{-/-}$. The Institutional Animal Care and Use Committee (IACUC) approved this study. Animals at selected stages of development were examined, and this study focused on newborn, postnatal day-2 (PN2), postnatal day-12 (PN12), and postnatal day-61 (PN61) mice.

\section{Genotyping of Rac1 alleles}

Genomic DNA was isolated by digestion in a buffer containing $0.6 \mathrm{mg} \mathrm{ml}^{-1}$ of proteinase $\mathrm{K}, 50 \mathrm{mM}$ Tris- $\mathrm{HCl}, \mathrm{pH}$ 8.0, $100 \mathrm{mM}$ EDTA, and 0.5\% SDS (Sigma, St Louis, MO, USA) at $55^{\circ} \mathrm{C}$ overnight. The solution was subjected to extraction with phenol, phenol/chloroform, and chloroform. DNA in the aqueous phase was precipitated by the addition of two volumes of ethanol. An additional wash step in $70 \%$ ethanol was essential to remove traces of SDS and phenol before biochemical manipulation. The PCR primers PO33 (TCCAATCTGTGCTGCCCATC), PO45 (CAGAGCTCGAATCCAGAAACTAGTA), and PO91 (GATGCTTCTAGGGGTGAGCC) were used in multiplex PCR reactions to differentiate the various wild-type, floxed Racl, or knockout Racl alleles. The PO33/PO45 primer pair was used to detect the 115-bp wild-type allele, the PO33/PO91 primer pair was used to detect the 242-bp floxed Racl allele, and the PO45/PO91 primer pair was used to detect the 140-bp knockout allele. The primer pair used to identify the 700-bp Cre allele was: forward primer, 5'-TGCTGTTTCACTGGTTATGCGG-3', and reverse primer, 5'-CCATTGCCCCTGTTTCACTATCC-3'.

\section{Backscattered electron imaging in the scanning electron microscope}

Hemimandibles of PN12 and PN61 wild-type or $\mathrm{Racl}^{-/-}$mice were dissected, fixed in $4 \%$ paraformaldehyde overnight, dehydrated in graded concentrations of acetone, and embedded in epoxy resin. Embedded blocks were sectioned in the coronal plane between the first and second molars, effectively sampling the mandibular incisor deep within the jaw at the same relative location for all specimens. One surface of each block was polished, made electrically conductive with a carbon coating, and examined in a Zeiss EVO-50 scanning electron microscope by backscattered electron imaging at high vacuum with an accelerating voltage of $50 \mathrm{kV}, 50 \mathrm{pA}$ specimen current, and a $9 \mathrm{~mm}$ working distance.

\section{Microcomputed tomography}

Mandibles from wild-type or $\mathrm{Racl}^{-/-} \mathrm{PN} 12$ or PN61 mice were dissected, fixed, and preserved in $70 \%$ alcohol. The samples were analyzed using the MicroCAT II (Siemens Medical Solutions, Knoxville, TN, USA). The microcomputed tomography images were acquired with an X-ray source operating at $80 \mathrm{kV}$ and $250 \mu \mathrm{A}$. The data were collected at $10 \mu \mathrm{m}$ resolution per voxel.

\section{Western blotting}

Protein recovery, resolution to size, and detection by a specific antibody was performed as previously described (19). Mandibular first molars from PN2 wild-type or $\mathrm{Racl}^{-}$ - mice were dissected and washed in ice-cold PBS, and then in $100 \mu \mathrm{l}$ of ice-cold RIPA buffer $(1 \times$ PBS, $1 \%$ Nonidet P-40, $0.1 \mathrm{mg} \mathrm{ml}^{-1}$ of phenylmethanesulfonyl fluoride, $30 \mu \mathrm{lml} \mathrm{l}^{-1}$ of aprotinin, and $1 \mathrm{mM}$ sodium orthovanadate) (Sigma). The lysate was cleared by centrifugation at $21,800 \mathrm{~g}$ for $15 \mathrm{~min}$ at $4^{\circ} \mathrm{C}$, and the protein concentration of the supernatant was measured using a Bio-Rad protein assay kit (Bio-Rad, Hercules, CA, USA) with serial dilutions of BSA as a standard. Experimental samples were electrophoretically resolved to size on a 4-12\% SDS-polyacrylamide gradient gel (Invitrogen, Carlsbad, CA, USA) and transferred to Immobilon-P membrane (Millipore, Temecula, CA, USA). The membranes were incubated in blocking buffer overnight at $4^{\circ} \mathrm{C}$, then incubated with primary antibody (chicken anti-recombinant mouse amelogenin polyclonal $\operatorname{IgY}(1: 3,000$ dilution $) \quad(20)$ or rabbit anti-recombinant rat ameloblastin polyclonal $\operatorname{IgG}(1: 2,000$ dilution) as previously described (21)] for $1 \mathrm{~h}$ and detected by incubation with a secondary antibody (horseradish peroxidase-conjugated anti-chicken or anti-rabbit $\operatorname{IgG}$ ) for $1 \mathrm{~h}$ at room temperature. Proteins were visualized by enhanced chemiluminescence (GE Healthcare, Pittsburgh, PA, USA).

\section{Immunohistochemistry}

Immunostaining was performed as described previously (22). Briefly, hemimandibles from newborn or PN2 wildtype and $\mathrm{Racl}^{-/-}$mice were dissected and fixed overnight in freshly prepared $4 \%$ paraformaldehyde in PBS, $\mathrm{pH} 7.4$, at $4^{\circ} \mathrm{C}$. Tissue sections of $6 \mu \mathrm{m}$ thickness were prepared and blocked to prevent non-specific absorption. After incubation with the selected primary antibody, the localization of the antibody-antigen complex was visualized with a suitable chromogen. Polyclonal anti-mouse amelogenin IgY (1:1,000 dilution) was raised in chicken and recovered from the egg yolk, an anti-chicken horseradish peroxidase-conjugated secondary antibody $\operatorname{IgG}$ (1:1,500 dilution), (Invitrogen), and a peroxidase substrate (AEC) was used for detection by local precipitation of the visible chromogen.

Unless stated otherwise all chemicals and reagents were from Sigma.

\section{Results}

\section{General phenotypes of Rac1 conditional knockout mice}

Approximately $60 \%$ of Racl-deficient mice were born dead, and pups alive at birth were indistinguishable from wild-type mice. However, within the first week of birth it became obvious that mice with the Racl deletion had a smaller body size, grew less hair, and displayed progressive hair loss, as reported previously (23). At PN12, the gross appearance of wild-type and $\mathrm{Racl}^{+/-}$animals was similar, while $\mathrm{Racl}^{-/-}$lost almost all of their body hair (Fig. 1A). Genotyping results are shown in Fig. 1 


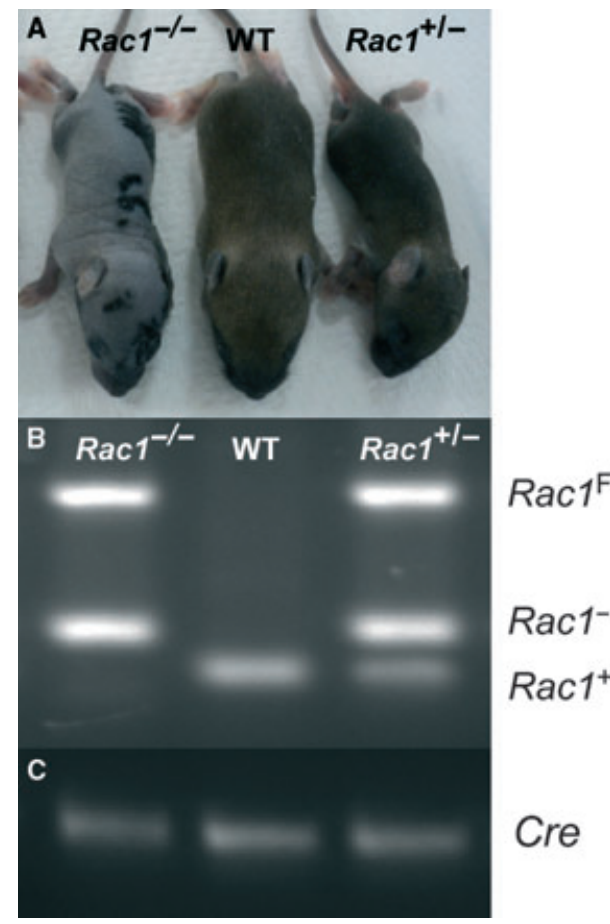

Fig. 1. Gross appearance and genotyping results of wild-type (WT) and $\mathrm{RaCl}^{-/-}$mice. (A) Gross appearance of postnatal day-12 (PN12) $\mathrm{Racl}^{-/-}$, WT, and $\mathrm{Racl}^{+/-}$animals. (B, C) Genotyping results of loxP-targeted $(\mathrm{F})$, wild-type $(+)$, and Cre-mediated recombination (-) for Racl alleles. The product sizes of the amplified alleles were: $242 \mathrm{bp}$ for the $R a c 1^{\mathrm{F}}$ floxed allele, $140 \mathrm{bp}$ for the $\mathrm{Racl}^{-}$knockout allele, $115 \mathrm{bp}$ for the $\mathrm{RaCl}^{+}$wild-type allele, and $700 \mathrm{bp}$ for the Cre allele.

B,C. The size of the amplified product for the $R a c 1^{F}$ floxed allele was $242 \mathrm{bp}$, that of the $\mathrm{Racl}^{+}$wild-type allele was $115 \mathrm{bp}$, and that of the $\mathrm{Racl}^{-}$null allele was $140 \mathrm{bp}$, as shown in Fig. 1B. The internal control of the Cre gene is shown in Fig. 1C. $\mathrm{RaCl}^{-/-}$mice had a shorter life expectancy compared with their wild-type siblings, and died at around 2-6 months of age from digestive tract defects (24).

\section{Dental defects in Rac1 conditional knockout mice}

$\mathrm{Racl}^{-/-}$mice were fully dentate, as observed grossly or in histological sectioning, or by image analysis. The appearance of PN12 mandibular incisors from wild-type (Fig. 2A) and $\mathrm{Racl}^{-/-}$(Fig. 2B) mice or of PN61 mandibular incisors from wild-type (Fig. 2C) and $\mathrm{Racl}^{-/-}$(Fig. 2D) mice is shown. Dental enamel in $\mathrm{RaCl}^{-/-}$mouse molars and incisors was abnormal, with a white or chalky appearance that lacked the iron pigment normally seen in wild-type mouse teeth. After tooth eruption, the enamel on the surfaces of incisors (Fig. 2) and molars (data not shown) was lost to abrasion or attrition through mastication.

Backscattered electron images, viewed by scanning electron microscopy, of the sectioned mandibular incisors from wild-type and $\mathrm{Racl}^{-/-}$mice are shown in Fig. 3. Enamel from $\mathrm{Racl}^{-/-}$mandibular incisors at PN12 (Fig. 3B,D) or PN61 (Fig. 3F,H) generated a
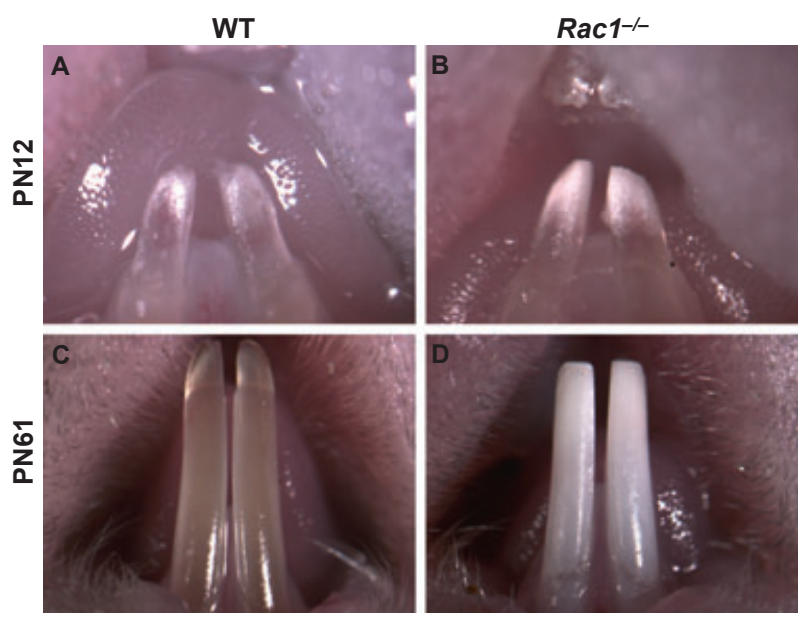

Fig. 2. Physical appearance of wild-type and $\mathrm{RaCl}^{-/-}$mouse mandibular teeth. Mandibular incisors of wild-type (WT) postnatal day-12 (PN12) (A) and postnatal day-61 (PN61) (C) mice are compared with those of $\mathrm{Racl}^{-1-} \mathrm{PN} 12$ (B) and PN61 (D) littermates, respectively. The appearance of the dental enamel in $\mathrm{Racl}^{-1-}$ incisors was abnormal, with a white chalky color. The enamel layer on the surface of incisors was almost entirely lost in PN61 Rac1 null mice (D).

reduced backscattered electron signal compared with enamel from wild-type littermates at PN12 (Fig. 3A,C) or PN61 (Fig. 3E,G), indicating that the enamel in the Racl-deleted mice is hypomineralized compared with wild-type controls. In addition, enamel from the Racldeleted mouse revealed modest disruption of the enamel rod architecture (Fig. 3D). Part of the enamel surface in PN12 $\mathrm{Racl}^{-/-}$mouse incisor appeared collapsed, as shown in Fig. 3B,D.

Micro-computed tomography images showed the presence of mandibular incisors and molars from PN12 and PN61 wild-type and $\mathrm{Racl}^{-/-}$littermates, respectively (Fig. 4). For both developmental periods, the images demonstrated a lower density of the enamel layer in the $\mathrm{RaCl}^{-/-}$mice (Fig. 4B,D) compared with that of wildtype mice (Fig. 4A,C). Notably, at PN61 the majority of the enamel layer from the incisor of the $\mathrm{Racl}^{-/-}$mice was lost from the incisal edge to the mid-length of the erupted incisor (Fig. 4D).

\section{Morphological characteristics of enamel-secreting ameloblasts}

Mouse mandibular incisors were chosen for this study because they display a gradient of ameloblast differentiation along their rostral-caudal longitudinal axis, with a stem cell population at their growing end that continues through to fully mature enamel at the most incisal end. Surprisingly, the microanatomy of the incisor tooth organ, including the ameloblasts, at the presecretory phase, reveals very few gross disturbances for the $\mathrm{Racl}^{-/-}$ (Fig. 5H) vs. wild-type (Fig. 5G) incisor teeth at PN2. It is not until the later stages of secretion that the major findings from the hematoxylin and eosin staining of these samples are revealed. Here, we found that the apical 

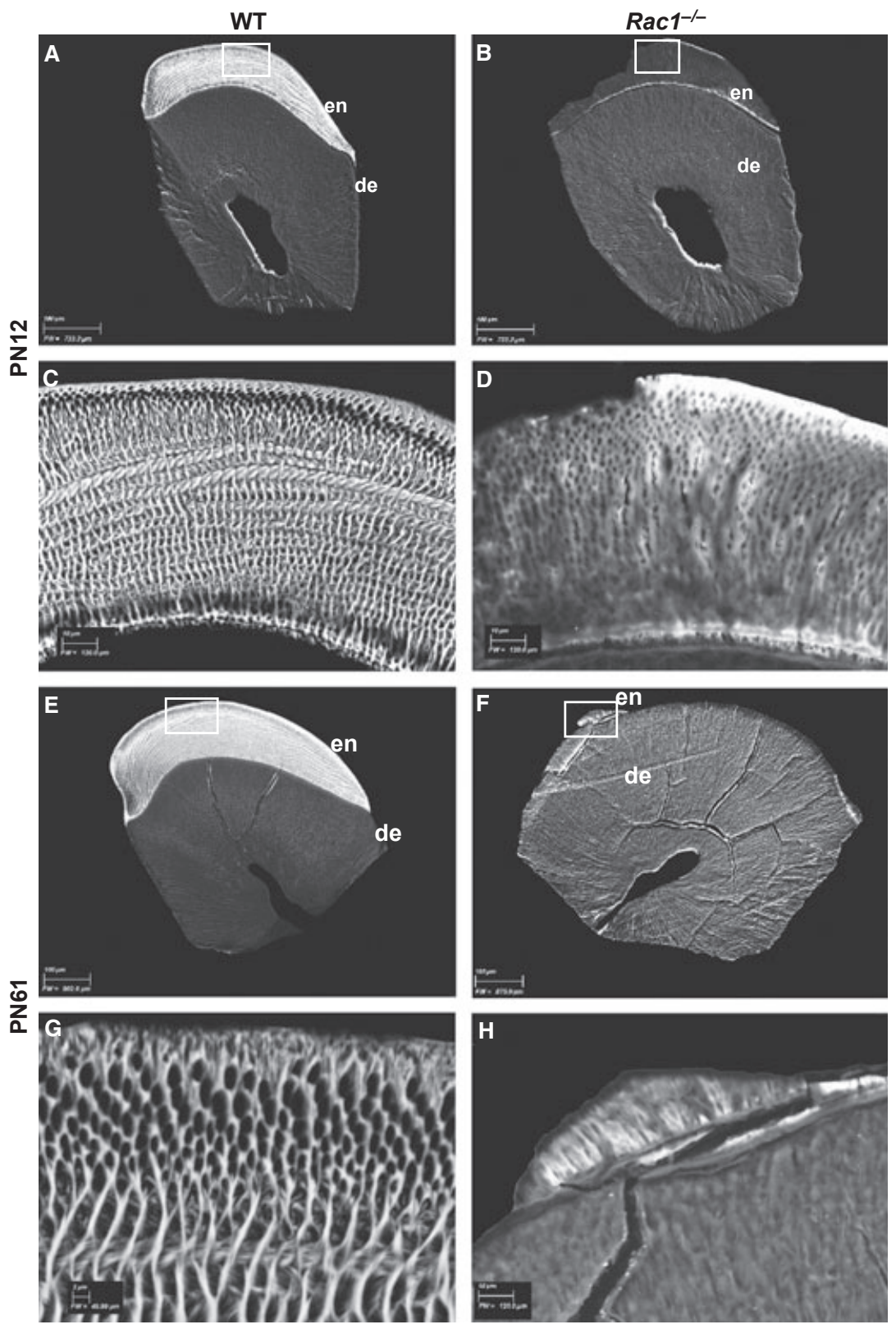

Fig. 3. Backscattered scanning electron microscopy images of mandibular incisors from wild-type (WT) and $R a c 1^{-/-}$mice are shown in cross-section. Mandibular enamel from postnatal day-12 (PN12) Racl ${ }^{-/}$(B, D) and postnatal day-61 (PN61) (F, H) mouse incisors generated a reduced backscattered electron signal compared with enamel from mandibular incisors of WT PN12 (A, C) and PN61 (E, G) littermates, respectively. de, dentin; en, enamel.

surface of enamel-secreting ameloblasts, known as Tomes' processes, at both early-secretory (Fig. 5F,L) and late-secretory (Fig. 5D,J) stages, became shortened and disoriented in Racl-deleted animals compared with wild-type secretory ameloblasts (Fig. 5E,K vs. Fig. 5C,I) at these same developmental stages, respectively. Although ameloblast cell polarity and columnar shape does not appear to be altered, the normal cell-cell and cell-enamel matrix contacts are lost in the unerupted mandibular incisor from the $\mathrm{Racl}^{-/-}$mouse along the entirety of the developmental gradient of palisading ameloblasts (Fig. 5D,F,H), compared with similar features from Racl wild-type mouse incisors (Fig. 5C,E,G).

\section{Enamel matrix proteins in Rac1 conditional knockout mice}

The expression of the two most abundant enamel matrix proteins secreted by ameloblast cells - amelogenin and ameloblastin - were examined by western blotting in mouse molars recovered from PN2 animals (Fig. 6). We found that the abundance of the major enamel matrix proteins, amelogenin (Fig. 6A) and ameloblastin (Fig. 6 B) were remarkably reduced.

We also examined amelogenin protein expression using immunohistochemistry techniques to determine if changes in expression levels had occurred in ameloblasts 

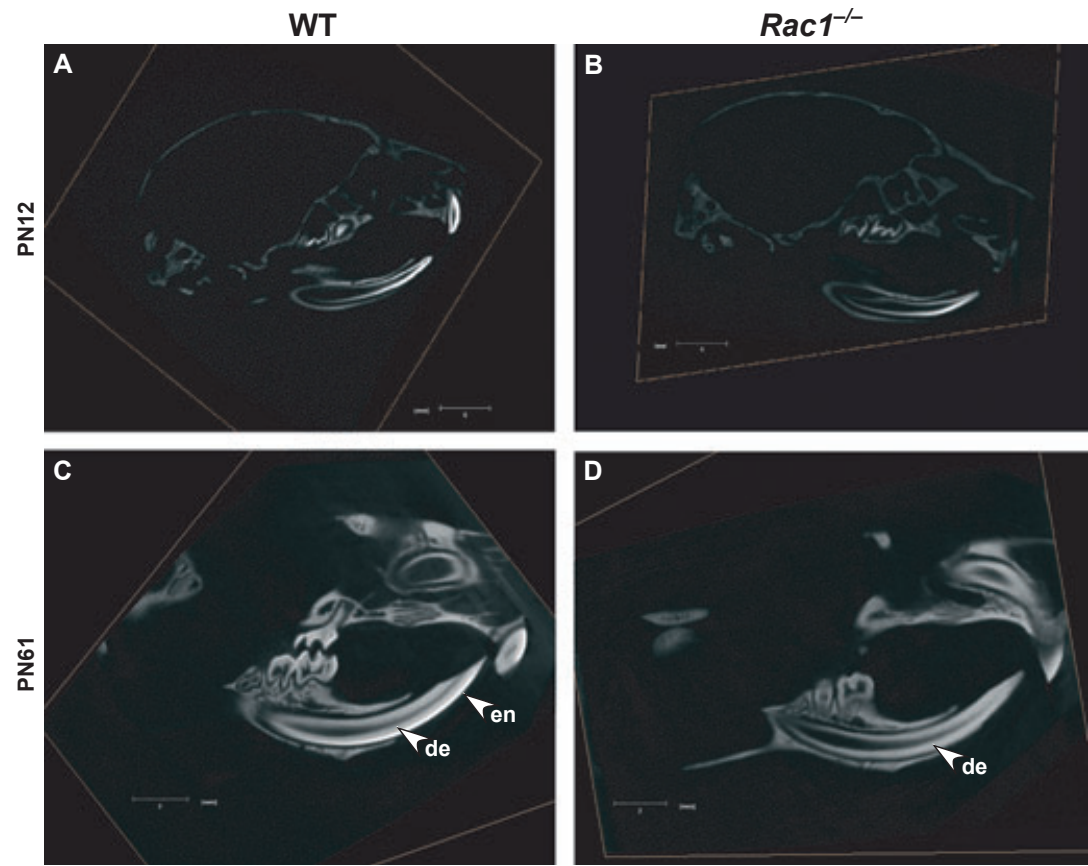

Fig. 4. Computed tomography of the heads from wild-type (WT) and $\mathrm{Racl}^{-/-}$mice. Mandibular incisors from WT postnatal day-12 (PN12) (A) and postnatal day-61 (PN61) (C) mice were compared with those from Rac ${ }^{-/-}$PN12 (B) and PN61 (D) littermates. PN61 $\mathrm{Racl}^{-/-}$mandibular molars and incisors (D) demonstrated abnormal, flat, and worn enamel. The enamel layer from the incisal edge to the mid-length of the erupted incisor in PN61 Racl ${ }^{-/-}$mice was lost (D). de, dentin; en, enamel.

globally or regionally with the elimination of the Racl gene. To accomplish this, we examined newborn incisors at a developmental site where amelogenin is initially secreted by newly differentiated ameloblasts (Fig. 7A,B). Immunostaining showed that while amelogenin was detectable, its abundance in newborn $\mathrm{Racl}^{-/-}$mouse mandibular incisor (Fig. 7D,F) was reduced compared with the corresponding features in wild-type ameloblasts (Fig. 7C,E).

\section{Discussion}

Tooth enamel formation, also known as amelogenesis, is coordinated with the formation of dentin by odontoblasts when the inner enamel epithelial cells proliferate and form the contours of the dentino-enamel junction. The inner enamel epithelial cells continue their exchange of signals with dentinoblasts, resulting in the elongation, polarization, and differentiation of pre-ameloblasts, which differentiate into secretory ameloblasts and form an enamel matrix. Initially, the ameloblasts make contact with the proteins within the basement membrane that separates the inner enamel epithelial cells from the presumptive dentinoblasts. With the synthesis and secretion of the enamel extracellular matrix, the Tomes' processes of the secretory ameloblasts remain in contact with the mineralizing enamel ceramic composite. Disturbances in either the process of ameloblast differentiation, or in the secretion or maturation of the enamel matrix can lead to defects in the enamel bioceramic $(20,25,26)$. Mutations in human genes such as amelogenin, X-linked $(A M E L X)$, enamelin $(E N A M)$, kallikrein-related peptidase 4
(KLK4), and matrix metalloproteinase 20 (MMP20) form the molecular basis for a series of defects in enamel formation known as amelogenesis imperfecta (AI). In AI, a defective protein structure encoded by the mutated gene can result in specific defects in enamel formation (27-30). Enamel from AI sources or teeth with enamel hypoplasia or hypomaturation accumulate mechanical defects that result in weak and easily damaged enamel.

The Rho family of small guanine nucleotide (GTP)binding proteins consists of RHO, RAC, and CDC42 subfamilies, among which RHOA, RAC1, and CDC42 are expressed and differently distributed at selected stages of tooth development and may play essential roles during amelogenesis. Recent studies showed that the abolishment of amelogenin mRNA expression and the loss of regular palisade-like organization of ameloblasts present in tooth germs cultured with Clostridium difficile toxin A inhibited all Rho-GTPase activity, while specific inhibition of Rock, an effector of the RhoA pathway, partially reduced the expression of amelogenin but predominately affected odontoblasts (31). The expression of a dominant negative RhoA in ameloblasts led to enamel hypoplasia with surface defects (32). However, the role(s) and function(s) of RAC1 during the formation and development of enamel have not been further elucidated. Experimentally, this can be accomplished by a gain-offunction approach, as in transgenic animals, or through loss of function in null animals. To avoid embryonic lethality, we used a loss of function approach restricted to a specific germ layer compartment by using a binary ablation technique. K14-Cre transgene-mediated DNA recombination occurs uniformly and consistently in enamel organ epithelia, as previously reported (19). 

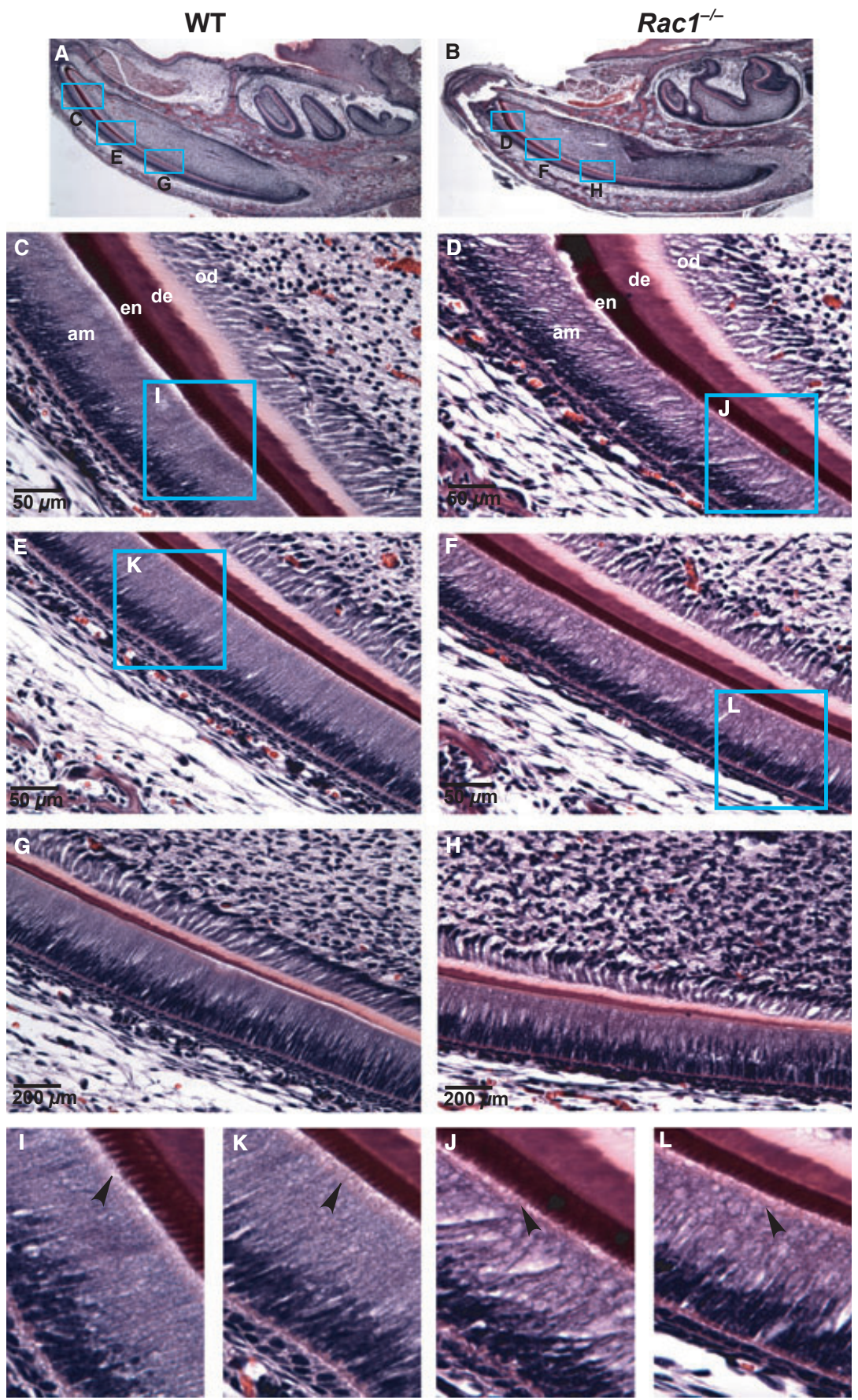

Fig. 5. Morphological characteristics of enamel-secreting ameloblasts from mandibular incisors of postnatal day-2 (PN2) wild-type (WT) and $\mathrm{Racl}^{-/-}$mice. Specific regions along the rostral-to-caudal developmental gradient of dental epithelia were chosen in order to study the cell microanatomy indicative of morphological differentiation in late secretory $(\mathrm{C}, \mathrm{D})$, early secretory $(\mathrm{E}, \mathrm{F})$, and late presecretory stage $(\mathrm{G}, \mathrm{H})$ ameloblasts in PN2 WT (A) and the $\mathrm{Racl}^{-/-}$mouse (B) mandibular incisor using standard hematoxylin and eosin staining. The Tomes' processes, specialized regions found at the apical end of ameloblasts, in early- (L), and late- (J) secretory stages of development, were shortened and lost contact with the forming enamel matrix in PN2 $\mathrm{Racl}^{-/-}$mouse when compared with early- (K) and late- (I) secretory ameloblasts in wild-type animal. am, ameloblast; de, dentin; en, enamel; od, odontoblasts.

In PN2 mouse molars from the Cre-mediated deletion of Racl, expression of both amelogenin and ameloblastin was significantly reduced; at PN12 and PN61, Rac1 conditional knockout mice exhibited disturbances to enamel formation, including the presence of hypoplasia and subsurface hypomineralization at various depths and to different extents, resulting in a phenotype similar to some forms of AI in humans. The dominant protein of mammalian enamel is amelogenin, while the second most abundant enamel structural protein of the forming enamel matrix is ameloblastin, also known as sheathelin $(20,33)$. Amelogenin and ameloblastin double-knockout 


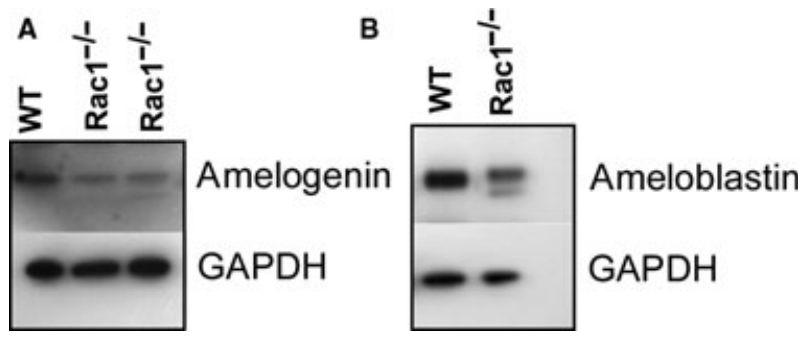

Fig. 6. Expression of enamel matrix proteins in postnatal day-2 (PN2) wild-type (WT) and $\mathrm{Racl}^{-/-}$mice. The expression of the dominant and second most abundant enamel matrix proteins secreted by ameloblast cells, amelogenin (A) and ameloblastin (B), were examined by western blotting of mouse molars extracted from WT or $\mathrm{Racl}^{-/-}$PN2 animals. GAPDH, glyceraldehyde-3-phosphate dehydrogenase.

mice showed additional enamel defects in comparison with amelogenin or ameloblastin single null mice, suggesting the synergistic roles of the dominant matrix proteins during enamel formation and mineralization
(34-36). Previous investigators have suggested that amelogenins are required for the organization and orientation of hydroxyapatite crystallites during enamel development, while ameloblastin is essential for maintaining ameloblast cyto-differentiation and cell attachment $(26,33,35,37,38)$. The decreased expression of amelogenin and ameloblastin in RAC1 conditional deleted mouse incisors supports a central role for $\mathrm{Racl}$ in acquiring and maintaining the state of ameloblast differentiation. Disruption between the integrins and other potential enamel matrix protein receptors are operationalized by the absence of the RAC1 protein in the null animals. The absence of RAC1 may also be responsible for the altered cell-matrix interaction observed in the Tomes' processes of the $\mathrm{Racl}^{-/-}$animals in this study.

Rho-GTPases mediate a variety of essential biological functions by triggering signaling pathways related to cell morphology and motility. The RHOA pathway is involved in cell cycle or gene transcription regulation during ameloblast differentiation (39). The RAC1 signaling pathway is known to regulate the formation of
WT
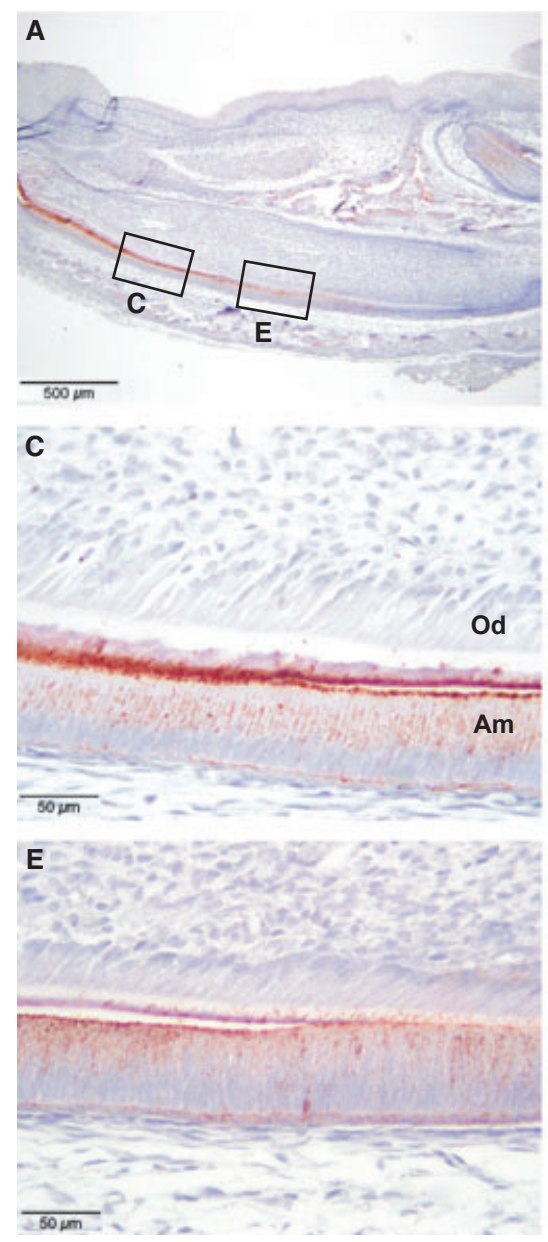
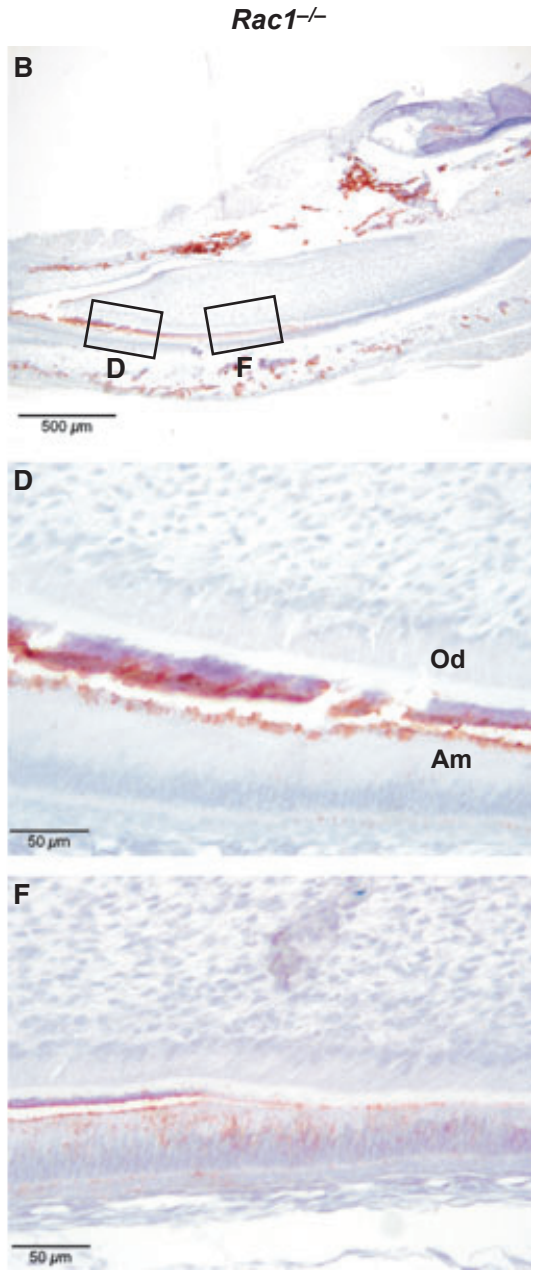

Fig. 7. Immunostaining of amelogenin in the sagittal sectioned mandibular incisors of newborn wild-type (WT) and Rac ${ }^{-/-}$mice. Amelogenin expression was detected along the developmental gradient of ameloblasts in newborn mandibular incisors from WT (A, $\mathrm{C}$ and E) or $\mathrm{Racl}^{-/-}$(B, D and F) mice. Specific regions from $\mathrm{Racl}^{-/-}$mice at an early secretory stage (box D) or a presecretory stage (box F) of development were compared with similar regions from WT animals (boxes C and E). Am, ameloblast; Od, odontoblast. 
fibroblast F-actin and the organization of actin cytoskeleton (40). RAC1 and CDC42 are suggested to affect cell polarity, cell spreading, and filopodia formation of the dental epithelium mediated by laminin-10/11 (41). In our study, disruption of Racl in dental epithelium has been shown to interfere with cytoskeleton organization of ameloblasts and cell-cell and cell-matrix contacts, as evidenced by the disorganized secretory ameloblasts, resulting in the loss of function for ameloblasts to regulate enamel matrix synthesis and mineralization.

In summary, RAC1 protein plays a crucial role in tooth enamel formation. The mechanism involved in RAC1 signaling in the dental epithelium needs to be further explored so that its role in modulating cell-matrix interaction during enamel formation can be better understood.

Acknowledgements - The University of Southern California Molecular Imaging Center provided MicroCAT II imaging and the authors are grateful for support from the National Institute for Dental and Craniofacial Research, NIH, USPHS through R01DE015920.

Conflicts of interest - The authors declare no conflicts of interest.

\section{References}

1. TheSLEFF I. The genetic basis of tooth development and dental defects. Am J Med Genet A 2006; 140: 2530-2535.

2. Jernvall J, Jung HS. Genotype, phenotype, and developmental biology of molar tooth characters. Am J Phys Anthropol 2000; 113 (Suppl 31): 171-190.

3. Fincham AG, Moradian-Oldak J, Simmer JP. The structural biology of the developing dental enamel matrix. $J$ Struct Biol 1999; 126: 270-299.

4. Sugihara K, Nakatsuji N, Nakamura K, Nakao K, Hashimoto R, Otani H, Sakagami H, Kondo H, Nozawa S, Aiba A, Katsuki M. Racl is required for the formation of three germ layers during gastrulation. Oncogene 1998; 17: $3427-$ 3433.

5. Noritake J, Fukata M, Sato K, Nakagawa M, Watanabe T, Izumi N, Wang S, Fukata Y, Kaibuchi K. Positive role of IQGAP1, an effector of Rac1, in actin-meshwork formation at sites of cell-cell contact. Mol Biol Cell 2004; 15: 1065-1076.

6. Thomas PS, Kim J, Nunez S, Glogauer M, Kaartinen V. Neural crest cell-specific deletion of Racl results in defective cell-matrix interactions and severe craniofacial and cardiovascular malformations. Dev Biol 2010; 340: 613-625.

7. Vidali L, Chen F, Cicchetti G, Оhta Y, Kwiatkowski DJ. Rac1-null mouse embryonic fibroblasts are motile and respond to platelet-derived growth factor. Mol Biol Cell 2006; 17: 2377 2390.

8. LiU S, KAPOOR M, LeASK A. Racl expression by fibroblasts is required for tissue repair in vivo. Am J Pathol 2009; 174: 18471856.

9. Cenny R. [Mineralized dental enamel matrix proteins]. Bratisl Lek Listy 2000; 101: 288-293.

10. Bei M, Stowell S, MaAs R. Msx2 controls ameloblast terminal differentiation. Dev Dyn 2004; 231: 758-765.

11. Huang Z, Sargeant TD, Hulvat JF, Mata A, Bringas P Jr, KoH CY, STUPP SI, SNEAD ML. Bioactive nanofibers instruct cells to proliferate and differentiate during enamel regeneration. J Bone Miner Res 2008; 23: 19950-20060.

12. Filipenko NR, Attwell S, Roskelley C, Dedhar S. Integrinlinked kinase activity regulates Rac- and Cdc42-mediated actin cytoskeleton reorganization via alpha-PIX. Oncogene 2005; 24 5837-5849.

13. DeMali KA, Wennerberg K, Burridge K. Integrin signaling to the actin cytoskeleton. Curr Opin Cell Biol 2003; 15: 572-582.

14. Boyde A. Correlation of ameloblast size with enamel prism pattern: use of scanning electron microscope to make surface area measurements. Z Zellforsch Mikrosk Anat 1969; 93: 583593.

15. Reith EJ, Boyde A. The arrangement of ameloblasts on the surface of maturing enamel of the rat incisor tooth. $J$ Anat 1981; 133: 381-388.

16. Nishikawa S, Fujiwara K, Kitamura H. Formation of the tooth enamel rod pattern and the cytoskeletal organization in secretory ameloblasts of the rat incisor. Eur J Cell Biol 1988; 47: 222-232.

17. Cutroneo G, Anastasi G, Donadio N, Favaloro A, Micali A, Nastro Siniscalchi R, Santoro G, Trimarchi F. Actinassociated proteins in ameloblast differentiation. Cells Tissues Organs 2002; 171: 128-134.

18. Glogauer M, Marchal CC, Zhu F, Worku A, Clausen Be, Foerster I, Marks P, Downey GP, Dinauer M, KwiatKOWSKI DJ. Racl deletion in mouse neutrophils has selective effects on neutrophil functions. J Immunol 2003; 170: 5652 5657.

19. Xu Y, Zhou YL, Gonzalez FJ, Snead ML. CCAAT/enhancer-binding protein delta (C/EBPdelta) maintains amelogenin expression in the absence of C/EBPalpha in vivo. $J$ Biol Chem 2007; 282: 29882-29889.

20. SNEAD ML. Enamel biology logodaedaly: getting to the root of the problem, or "who's on first...". J Bone Miner Res 1996; 11: 899-904.

21. Krebsbach PH, Lee SK, Matsuki Y, Kozak CA, Yamada KM, YAMADA Y. Full-length sequence, localization, and chromosomal mapping of ameloblastin. A novel tooth-specific gene. J Biol Chem 1996; 271: 4431-4435.

22. Couwenhoven Ri, Luo W, Snead ML. Co-localization of EGF transcripts and peptides by combined immunohistochemistry and in situ hybridization. J Histochem Cytochem 1990; 38: 1853-1857.

23. Chrostek A, Wu X, Quondamatteo F, Hu R, Sanecka A, Niemann C, Langbein L, Haase I, Brakebusch C. Racl is crucial for hair follicle integrity but is not essential for maintenance of the epidermis. Mol Cell Biol 2006; 26: 69576970.

24. Castilho RM, Squarize CH, Patel V, Millar Se, Zheng Y, Molinolo A, GutKind JS. Requirement of Racl distinguishes follicular from interfollicular epithelial stem cells. Oncogene 2007; 26: 5078-5085.

25. Paine ML, Snead ML. Tooth developmental biology: disruptions to enamel-matrix assembly and its impact on biomineralization. Orthod Craniofac Res 2005; 8: 239-251.

26. SNEAD ML. Amelogenin protein exhibits a modular design: implications for form and function. Connect Tissue Res 2003; 44 (Suppl 1): 47-51.

27. Rajpar MH, Harley K, Laing C, Davies RM, Dixon MJ. Mutation of the gene encoding the enamel-specific protein enamelin, causes autosomal-dominant amelogenesis imperfecta. Hum Mol Genet 2001; 10: 1673-1677.

28. WRIGHT JT. The molecular etiologies and associated phenotypes of amelogenesis imperfecta. Am J Med Genet A 2006; 140: 2547-2555.

29. Hart PS, Hart TC, Michalec MD, Ryu OH, Simmons D, HoNG S, Wright JT. Mutation in kallikrein 4 causes autosomal recessive hypomaturation amelogenesis imperfecta. $J$ Med Genet 2004; 41: 545-549.

30. Hart PS, Aldred MJ, Crawford PJ, Wright NJ, Hart TC, WRIGHT JT. Amelogenesis imperfecta phenotype-genotype correlations with two amelogenin gene mutations. Arch Oral Biol 2002; 47: 261-265.

31. Biz Mt, Marques mr, Crema Vo, Moriscot AS, dos Santos MF. GTPases RhoA and Racl are important for amelogenin and DSPP expression during differentiation of ameloblasts and odontoblasts. Cell Tissue Res 2010; 340: 459-470. 
32. Li Y, Pugach MK, Kuehl MA, Peng L, Bouchard J, Hwang SY, Gibson CW. Dental enamel structure is altered by expression of dominant negative RhoA in ameloblasts. Cells Tissues Organs 2011; 194: 227-231.

33. Fukumoto S, Kiba T, Hall B, Iehara N, Nakamura $\mathrm{T}$, Longenecker G, Krebsbach PH, Nanci A, Kulkarni AB, YAMADA Y. Ameloblastin is a cell adhesion molecule required for maintaining the differentiation state of ameloblasts. $J$ Cell Biol 2004; 167: 973-983.

34. Gibson CW, Collier PM, Yuan ZA, Chen E, AdelekeStainback P, Lim J, Rosenbloom J. Regulation of amelogenin gene expression. Ciba Found Symp 1997; 205: 187-197; discussion 197-189.

35. Gibson CW, Yuan ZA, Hall B, Longenecker G, Chen E, Thyagarajan T, Sreenath T, Wright JT, Decker S, Piddington R, Harrison G, Kulkarni AB. Amelogenin-deficient mice display an amelogenesis imperfecta phenotype. $J$ Biol Chem 2001; 276: 31871-31875.

36. Hatakeyama J, Fukumoto S, Nakamura T, Haruyama N, Suzuki S, Hatakeyama Y, Shum L, Gibson CW, Yamada Y, KULKARNI AB. Synergistic roles of amelogenin and ameloblastin. J Dent Res 2009; 88: 318-322.
37. Hunter GK, Curtis HA, Grynpas MD, Simmer JP, Fincham AG. Effects of recombinant amelogenin on hydroxyapatite formation in vitro. Calcif Tissue Int 1999; 65: 226-231.

38. Fukumoto S, Yamada A, Nonaka K, Yamada Y. Essential roles of ameloblastin in maintaining ameloblast differentiation and enamel formation. Cells Tissues Organs 2005; 181: 189-195.

39. Li Y, Decker S, Yuan ZA, Denbesten PK, Aragon MA, Jordan-Sciutto K, Abrams WR, Huh J, McDonald C, Chen E, MacDougall M, Gibson CW. Effects of sodium fluoride on the actin cytoskeleton of murine ameloblasts. Arch Oral Biol 2005; 50: 681-688.

40. Albertinazzi C, Cattelino A, de Curtis I. Rac GTPases localize at sites of actin reorganization during dynamic remodeling of the cytoskeleton of normal embryonic fibroblasts. J Cell Sci 1999; 112 (Pt 21): 3821-3831.

41. Fukumoto S, Miner JH, Ida H, Fukumoto E, Yuasa K, MiYazaKi H, Hoffman MP, Yamada Y. Laminin alpha5 is required for dental epithelium growth and polarity and the development of tooth bud and shape. $J$ Biol Chem 2006; 281: 5008-5016. 